\title{
Distant places in children's everyday activities: Multiple worlds in an Australian preschool
}

\section{Zsuzsa Millei}

Abstract: Global flows and their geopolitical power relations powerfully shape the environments in which children lead their everyday lives. Children's images, imaginations and ideas of distant places are part of these global flows and the everyday activities children perform in preschool. Research explores how through curricula young children are moulded into global and cosmopolitan citizens and how children make sense of distant places through globally circulating ideas, images and imaginations. How these ideas, images and imaginations form an unproblematised part of young children's everyday preschool activities and identity formation has been much less explored, if at all. I use Massey's (2005) concept of a 'global sense of place' in my analysis of ethnographic data collected in an Australian preschool to explore how children produce global qualities of preschool places and form and perform identities by relating to distant places. I pay special attention to how place, objects and children become entangled, and to the sensory aspects of their emplaced experiences, as distant spatialities embed in and as children's bodies inhabit the preschool place. To conclude, I call for critical pedagogies to engage with children's use of these constructions to draw similarities or contrast aspects of distant places and self, potentially reproducing global power relations by fixing representations of places and through uncritically enacting stereotypes.

Keywords: globalisation, early childhood education, cosmopolitanism, global sense of place, ethnography. 


\section{Introduction}

The integration of education systems worldwide into the global knowledge economy, concerns about sustainability, the ubiquitous presence of popular cultures and the new media, and the increased mobility of ideas, things and people all powerfully shape the environments in which children lead their everyday lives (Mitchell \& Reid-Walsh, 2002; Ansell, 2009; Penn, 2002; 2011; Millei \& Jones, 2014). Within this context, policy frames of international and national early childhood education and care (ECEC) position children as the global and cosmopolitan citizens of the future (James \& Prout, 1997; Prout, 2005, Hägglund \& Pramling Samuelsson, 2009; Penn, 2011). To facilitate children's knowledge about their world, curricula are designed to create geographical imaginations of places on a variety of scales, such as children's locality, their region, country and distant places. In relation to this they are also aimed at intentionally shaping open minded and responsible global citizens for the future (Duhn, 2006, 2014; Hägglund \& Pramling Samuelsson, 2009; Millei \& Jones, 2014; Jones, 2017).

Global flows, power relations and changes intertwine in dynamic exchange with the places children inhabit, and research in children's geographies brings to the fore the complex ways they shape children's experiences and identities (e.g. Katz, 2004; Hackett, Procter \& Seymour, 2015). There is also a growing body of work exploring what children know and the processes they use to construct knowledge about distant places and form identities in relation to them (Holloway \& Valentine, 2000b; Disney, 2005; Picton, 2008; Taylor, 2009). In this paper, I bring together these bodies of work and explore how images, ideas and imaginations of distant places form a part of the everyday preschool activities young children perform that lend the preschool space a global quality and provide positionings for children's identity formation.

Despite the global situatedness of children's present and future lives, research in the fields of childhood studies and children's geographies is mostly framed as intimate geographies of local (see McKendrick, 2000; Ansell, 2009) and within institutional spaces of ECEC (see Bollig, 2015). This kind of delineation restricts consideration of how children's lives are embedded in global processes or how they have relevance to their identities and learning that pedagogies and curricula are designed to shape. To put it differently, while children are seen as developing global and cosmopolitan citizens, and learners, who are required to acquire knowledge and maintain responsible relations to the world and others, considerations about the embeddedness 
of their present lives in global flows and power relations remain limited to the local. The ways in which children negotiate globally circulating images, ideas and imaginations and perform or create identities related to those in their everyday lives in ECEC are less deliberated in research and ECEC practice. In this paper I set out to remediate that situation.

By drawing on ethnographic data I illustrate the kinds of images, ideas and imaginations of distant places 4-5 year old children draw on in their everyday activities in an Australian preschool. Here I understand 'distant place' to mean one located outside the national borders of Australia. Australia is a large country so there are plenty of distant places within it. Here, however, I focus on non-Australian places because the Early Years Learning Framework (AGDEEWR, 2009) specifically states in relation to one learning outcome that children need to create connections with and contribute to their world (see Duhn, 2014; Millei \& Jones, 2014). I also explore how those images infuse global qualities into the preschool place and into the children's performance of their identities. Like Massey (1998), I see quality of place "as an articulation of contacts and influences drawn from a variety of places" (p. 124) and "the construction of [the] spatiality" of the preschool as "an important element in building a social identity" (p. 128). It is in this way that I see the world appearing in the preschool, as it is spatiality negotiated by the children and as it is constructed through the spatial performance of their identities.

Place, objects and children become entangled as children's bodies inhabit the preschool place. Pink's (2009) notion of emplacement refers to this entanglement and emphasises its sensory aspects. There is repeated discussion in childhood studies of the idea that children's experiences of place are more embodied and sensory than adult experiences, and have greater intensities of affect (Christensen, 2003; Hackett, Procter \& Kummerfeld, 2018). The sensory aspects of place generate emplaced knowledge as children move through place with their bodies, and over time children attach meanings and memories to place (Christensen, 2003). Emplaced knowledge is distinct from spatial knowledge (abstract, generalised, represented in maps). Drawing on the notion of emplaced knowledge not only enables me to shift my exploration from understanding distant places as spatial knowledge (related to cognition, sense-making and idea construction), but also helps me to research how spatial knowledge, objects and affects come together within that place to produce embodied sensory experiences that form knowledge embedded in children's everyday activities and offer subjective positionings. In the next sections, I continue by further outlining the conceptualisation of 
this project and offer some methodological considerations of how the concepts were operationalised in collecting and interpreting the data. In the analytical part that follows, I have selected situations in which objects, embodied experiences and affects have prominent roles in producing the global qualities of place in which children are emplaced. To conclude, I draw some considerations on pedagogies that help children create more critical connections with the world.

\section{The Preschool, the Child and the 'World'}

To conceptualise my exploration of how children draw on images, ideas and imaginations of distant places in their everyday activities, I draw on a relational view of place within spatial theorising. The place of the preschool, while bound by its walls and institutional practices, is also porous, and is produced through its connections with wider societies (Holloway \& Valentine, 2000a). Massey (1991) conceptualised this relational view of space and developed an approach in which space is bound into the local and global networks that act to configure particular local places. Places can thus be imagined as "articulated moments in networks of social relations and understandings" (Massey, 1991, p. 28). This means that a relational understanding of place goes against any fixed or absolute conception of place. Place is continuously invested with meanings and 'doings' in relations to other places and times, thus place is bound into particular processes of space-time constitution. The place of the preschool thus is not a container in which social action takes place, but is socially produced in each given moment and as connected to other places and societies.

The notion of a 'global sense of place' is a consequence of this relational understanding of place. Place has 'roots', attached to a geographical locale, but also 'routes' that connect place to other spaces and places. 'Routes' function through a vast complexity of interconnections that form meanings in space, often as embodied experiences (Massey, 1994). For example, these 'routes' connect the preschool to global agencies (e.g. Organisation for Economic Co-operation and Development, World Bank), research institutions (e.g. brain research at Harvard University or Save the Children UK pioneering the Child Development Index) or institutions representing global trends (e.g. Reggio Emilia). Ideologies or best practice prescriptions originating at these distant places connect through different 'routes' and shape how the preschool is experienced. 'Routes' are also associated with mobility and access, and that in turn shifts understandings of locality and connections across space and place (Secor, 2004). 'Routes' also bring material and se- 
miotic conditions and resources to a place, and these then feed into the 'sense of place' and its culture. Thus, the preschool is not only rooted in a particular place but it is also routed, its hybrid places are organised through interconnections to other places. Consequently, the 'routes' and 'roots' experienced in a place or by a person are crucial to the formulation of place and identities.

As Massey (1998, p. 124-125 original emphasis) expresses it, place is "constellations of temporary coherence... set within a social space which is the product of relations and interconnections from the very local to the intercontinental". Massey emphasises that these relations are imbued with power that directs cultural influences. Places also have roots that hold multiple interpreted histories, experiences, knowledge and spatial connotations. For example, Penn (2011) in her study of international NGOs operating in ECEC in the Global South shows how common discourses between these organisations originate in the Global North, especially in North America. However, as they encounter local histories and knowledges, and the experiences of those concerned with early childhood programmes and policies, equity and quality arguments are downplayed and investment arguments are overplayed in the interpretations of those discourses. These cultural lines of connections "are expressions in one way or another of solidarity or of a desire to belong to something believed in" (Massey, 1998, p. 125), as in the example of actors in the South wishing to apply scientifically sound, universally applicable precepts about child development (Penn, 2011). These connections also have implications for identity, since these actors may be applying these views so they are seen as and act as professionals in the eyes of their global North counterparts.

Massey (2005) suggests that place is the multiple objects, bodies, beings, 'roots' and 'routes' that constitute place in a dynamic manner. The presence, or absence, of these play a role in altering spaces, in the continuous production of place, and in making and breaking connections. They also invest the place of the preschool with objects, bodies, images, ideas, imaginaries, practices and power relations, and shape that place. In this dynamic, individuals and social groups are constantly engaged in efforts to make connections, territorialise space, claim spaces and include and exclude others. As I will show in the situations below, objects, such as a dress or a tent, can create new connections between the preschool and a distant place, such as Indonesia or Buenos Aires, and children can use them in their continuous production of place as connected to these places. Productions of place include territorialisation, fencing and bordering, in the sense that for example 
a tent can be a distinct place from the preschool and children can exclude those who do not belong. Thus, the production of place has a lot to do with the social production of identities, of who we are and who the others are (those not included). The diverse senses of place these objects, images, bodies and so on, and the dynamic spatiality created by the preschool's social life also tell us something emotional about a place, for example, relating to inclusions and exclusions or the objects, images and so forth connect places that carry emotions or remind us of attachments.

Identities, which are continuously and contextually shifting and fluid, are produced through a performative, spatial and embodied process (Gregson $\&$ Rose, 2000). Here performative and embodied refer to Butler's (1990) notion of performativity: the ways in which particular subjectivities are formed through the submission (habituation) of bodies to discursive practices. Social norms within these discourses inscribe the body through repetitive and reiterative acts. The spatial refers to 'spaces of embodiment' (Crang \& Thrift, 2000). Objects also gain meaning and possible uses / actions (embodiment) mediated by space. If we observe a child acting within the context of an object world, we can see that an object's meanings and even its embodied nature, and the norms the child follows in acting with that object, are acquired through the construction of that space. Thus, space is actively present in the child's social practice and is imbued with social norms that produce identities. In this way, identities are produced and performed in space, "in and through social action rather than existing anterior to social processes" (Gregson \& Rose, 2000, p. 434). At the same time, the spaces in which children perform these identities "do not pre-exist their performances, waiting in some sense to be mapped out by performances; rather, specific performances bring these spaces into being" (Gregson \& Rose, 2000, p. 441).

This understanding also has consequences for how we see the world, as in, for instance, the curriculum framework for Australian preschools. Based on the previous arguments then, the 'world' is not a pre-existing space or place or a place or space that can be pre-defined. Rather it is produced and reproduced through social actions within the relations of objects, images, ideas, imaginations and people, and at the same time it is a space of embodiment. It is a space that participates in the construction of place in which performances of identity take place and in which children can produce and reiterate identities in relation to the 'world' 'brought to life' by them through their embodied performances (Thrift \& Dewsbury, 2000). In the next section, I discuss how I operationalised these concepts in my ethnographic project and analysis. 


\section{Methodological Considerations}

I conceptualised the original project as 'placemaking' in a globalising world as a means of exploring how, within the context of mobility and globalisation, children produce spaces within their preschool that engage with and are situated within these processes. This then helped me to shift my gaze away from looking at how the 'global', both on the larger scale containing the locale of the preschool and as a predefined and pre-exiting idea or abstract concept, shapes and influences the preschool space or is brought into the preschool by children knowing about it. Children themselves produce the world or the 'global' by referencing distant places or engaging with objects, people, relations, images or imaginations that create connections with distant places. Considering how space is produced within this created context of the world, it is important to focus on how this place is entangled within the broader politics of space, social relations and power, as Massey (2005) suggests.

Over the course of 18 months in 2013 and 2014, I collected ethnographic data to document children's lives in situations where reference was made to distant places, or in which objects, people or relations appeared, which were connected to or originated from distant places. I aimed to shift attention away from children's sensemaking towards the situation and process of experiencing to create accounts of their sensory emplacements (Pink, 2009). In focusing on children's emplacement in spaces, I collected data that approximated sensory experiences and movements, bodily sensations, objects and intensities of affect in children's everyday activities. I paid attention to bodily positions and expressions, touches, feelings, objects, sensory and affective relations with objects and people, and the affective force of various situations.

As an ethnographer, I was located in the preschool, but I also followed the children to regular activities outside the preschool, such as excursions. I investigated the children's stories: for example, if a person travelled with a child who had brought an object as a souvenir to the preschool, then I asked that person about the trip. I traced images, ideas or stories that the children got from books or the media. I gave the children cameras and asked them to take photos and videos of the distant places they visit or visited. I asked them to bring in objects or take photos of objects they considered important. Later we discussed these photos and told stories about the objects.

As an ethnographer who was also a migrant to Australia, I was emplaced in the research context which helped me engage with the children's em- 
placed experiences (Pink, 2009, p. 25) and emotions. As Procter (2013, p. 81) explains, emotions circulate in research situations, since "emotions are also bound up in the researcher's relational emplacement within and as part of the field site". In agreement with Procter $(2013$, p. 81) I see this entanglement as being productive for research since "emotional reflexivity connects the researcher with the social processes through which spatialised feeling rules are sustained, contested or transformed". Consequently, this reflexivity can be used to help understand children's socio-emotional practices. I not only participated in children's activities but also in conversations where attempts were made to elicit children's thinking, reflection and actions. The children reflected on my presence, noticed or criticised my accent, and invited me to participate or excluded me. Participating in this way also involved intervening when a child or a group discriminated against another or when I encountered unjust or harmful discourses and practices that also triggered emotional reactions in me (Millei \& Rautio, 2017).

Being well acquainted with the literature on researching with children, I tried to position myself as a slightly unconventional adult. I played with the children and never acted as their teacher. I also followed the literature on research ethics, protocols, and mechanisms for engaging with children, reflected in the Convention on the Rights of the Child (United Nations High Commissioner for Human Rights, 1989). I repeatedly asked the children for their consent throughout the project and before presenting and publishing data relating to them. However, as one of the situations shows, sometimes my quest to collect data or the excitement of the research moment overshadowed the need to ask for consent. Since the project activities ran concurrently with other curricular activities, the children usually decided to freely take part and I did not appear to disturb the usual running of the day when I was just sitting in on or observing an activity. Due to Australian ethics policies, I have opted to use pseudonyms in this article, although some children and their parents stated they did not mind if I used their real names.

For this paper, I have selected situations in which special places, objects, embodiment and affective intensities play a part in how children bring to light the world with images, ideas and imaginations about distant places. The analysis presented in this paper is based on video-recorded data that helped me to identify the detail needed to draw out the sensory experiences. The data presented here stems from my embodiment and emplacement as an ethnographer participating in a place with the children, and from my analytical interpretations of the embodiment of the children and objects and affective intensities, including my own 'sensory clues' (Procter, 2013, p. 83). 


\section{Distant Places within the Preschool}

In this first situation and analysis, I pay attention to how children territorialise a place within the preschool by drawing on an image of a distant place, connecting their imagination of that distant place with the preschool place. The produced place then offers them opportunities to perform their identities in relation to the preschool's social norms and the distant place imagined.

\section{Tent in Buenos Aires}

The teacher reads a Madeleine book to a group of children. The inside back cover is a picture of the Plaza de la República in Buenos Aires with the Obelisk of Buenos Aires. Inspired by the book, the children build a tent in the garden. It is constructed out of a large blue plastic sheet hanging on a rope secured between two branches of a tree providing shade and separating the area from the rest of the outside play area. The many blankets and pillows on the floor make the tent cosy. The teacher invites me to come and see the tent and the picture the children used to mark it. She knows I have just returned from a trip to Buenos Aires.

I am very excited by the invitation as that morning I have brought some photos of my recent trip on my computer and am eager to show them to the children. I have a photo of the very same square. I invite some of the children to look at the photos but they are not interested. As I reach the tent I see the image of the square copied from the book hanging above the tent's entrance, just like in my photo. The children exclaim with excitement: "It's our home in Buenos Aires!" I pull up some photos on my computer portraying the same square. The photos show the Obelisk, the large red drums used in building construction that were ongoing at the time of my visit. The children identify the square and some details in the pictures and suggest, "We need a tin (Louise looks up and points to the top of the tent), because we want to have our own kind of one". The children point to the tall houses, observe the lack of street lights and the stray dogs in other photos. They don't always understand my words and explanations of the photos and ask me to say it again and clarify. The children soon declare: "We're going to sleep now." They crawl to the back of the tent and organise the pillows and cover themselves with the blankets. While I watch them getting into their beds and think of how I can join them they add: "There is no place for you". 
The picture of the Plaza de la República hanging above the tent's entrance signals the tent's location. It creates a symbolic connection between the place in the preschool garden and the place in Buenos Aires. The children seem to be emplaced in both places at the same time. The objects portrayed are part of the distant place: the picture of the square, the tins, the dogs, the tall buildings and the lack of street lights all help produce their emplacement together with the materiality of the pillows and the cosy feeling of being in the tent. The familiarity of being in the tent and the less familiar images of Buenos Aires blend together in their emplacements.

The blue sheet of the tent creates seclusion and cosiness and separates this place off from the children's regular preschool environment. In the regular environment of the preschool garden, where the children are 'rooted', they have habituated relations to the environment which offer them certain positions from which to perform their identities. To some degree the fact that this space is separated off and conflated with the distant place of Buenos Aires liberates the children's bodies from their usual habits, rules and regulations and constraints, but also presents the possibility of performing new identities. The place of the preschool is opened up by the act of connecting it to this distance place, and the sensations of being here and there at the same time, and it is from this that the activities emerge. They can act as people or children living in Buenos Aires, with dogs, constructing things from tins, walking in the streets, playing in the preschool tent and so on.

The discursive norms of the preschool dictate that the children should follow the preschool rules. One of these rules is that the children have to respect any adults present, even if they have not invited that adult to play with them. When I arrive I show them and talk about my photos and they listen. It is possible that they are interested in my photos because they add to their imaginations of this distant place. At the end, however, they exclude me from joining them in their tent. As I was not invited, I do not protest. However, it also occurs to me that their being in Buenos Aires, and positioning themselves as 'fitting' citizens there, presents them with a way of excluding me, since I am an adult and I am also different, and perhaps do not belong in their imagination of Buenos Aires. After all, I had imposed my presence on them when they were playing and had forgotten to ask for their consent. I also feel that my accent may have played a role in their exclusion of me. This is a reasonable interpretation since previously on many other occasions the children had associated language differences with different spaces: they had told me that in Africa people speak Spanish or that in France people speak French and so on. Many of them, including one of the 
girls in the tent, had also asked me repeatedly what language I was speaking as she did not understand me. This was despite the fact we were conversing in English. Excluding me could therefore adds another binary construct between self and other, adult and child, play-friend and not play-friend. The children attach a language difference to the distant place, and I do not speak their language. As Picton (2008) observed in his research with middle school children, imaginations and stereotypes connected to distant places help children diversify binary contrasts between self and other.

The place of the tent could also be considered as a place for symbolic play. Symbolic play includes planning outside the playframe and acting within the playframe within which children assume the dual roles of narrators who describe what the figures are doing, and of vicarious actors who act for the figures. Symbolic play draws on social knowledge and the representation of social events and the internal states of the figures in a dynamic way. Symbolic play constitutes play with the ability of children to represent the real world (Bretherton, 1984). In their tent, the children perform their social knowledge about this distant place. They make connections between their tent scenario and life in Buenos Aires; thus they imagine this distant place as a continuum of their experience in the tent. In their symbolic play the children act out living in the tent, and maybe also in Buenos Aires, and by doing so connect these places through common ground and help produce a sense of the world.

The picture of the square and the tent helped the children to mark their place and territorialise a part of the preschool garden area. Other objects also played an important role in their engagement with distant places in the preschool. In this next situation, a dress brought from a distant place creates a new 'route' with a distant place and the preschool.

\section{Kylie's dresses (Figure 1)}

Dressed in a red silk dress with golden floral embroidered sequins Kylie enters the preschool. Kneeling and constantly stroking her body with her hands to feel the soft, shiny silk Kylie tells me the story of how this 'Chinese dress' had been given to her by her father who frequently travels to Asia, and had brought this dress from Indonesia. While she is speaking to me Kylie's eyes and hands dart to the intricate flowers, the pleasant feel of the silk and the golden threads. "Who do you think wears this kind of dress in Indonesia," I ask. "There are different kinds of dresses." "Do you think this is for children?" "Yes," she responds. "Do you think children wear this dress in Indonesia?" "This is a dress 
for all different kinds of places." "Like what?" I ask. "Like at school." "Do you know I live on a farm?" "And do you wear this dress there?" She nods, her eyes widening as she tells me how it had been the middle of the night when her father arrived and in the morning the dress was there. She tells me that she owns lots of dresses from her father's trips to different countries in Asia. "I told dad to buy this dress and he did." I asked Kylie to take my camera home with her and take some photos of the other dresses.

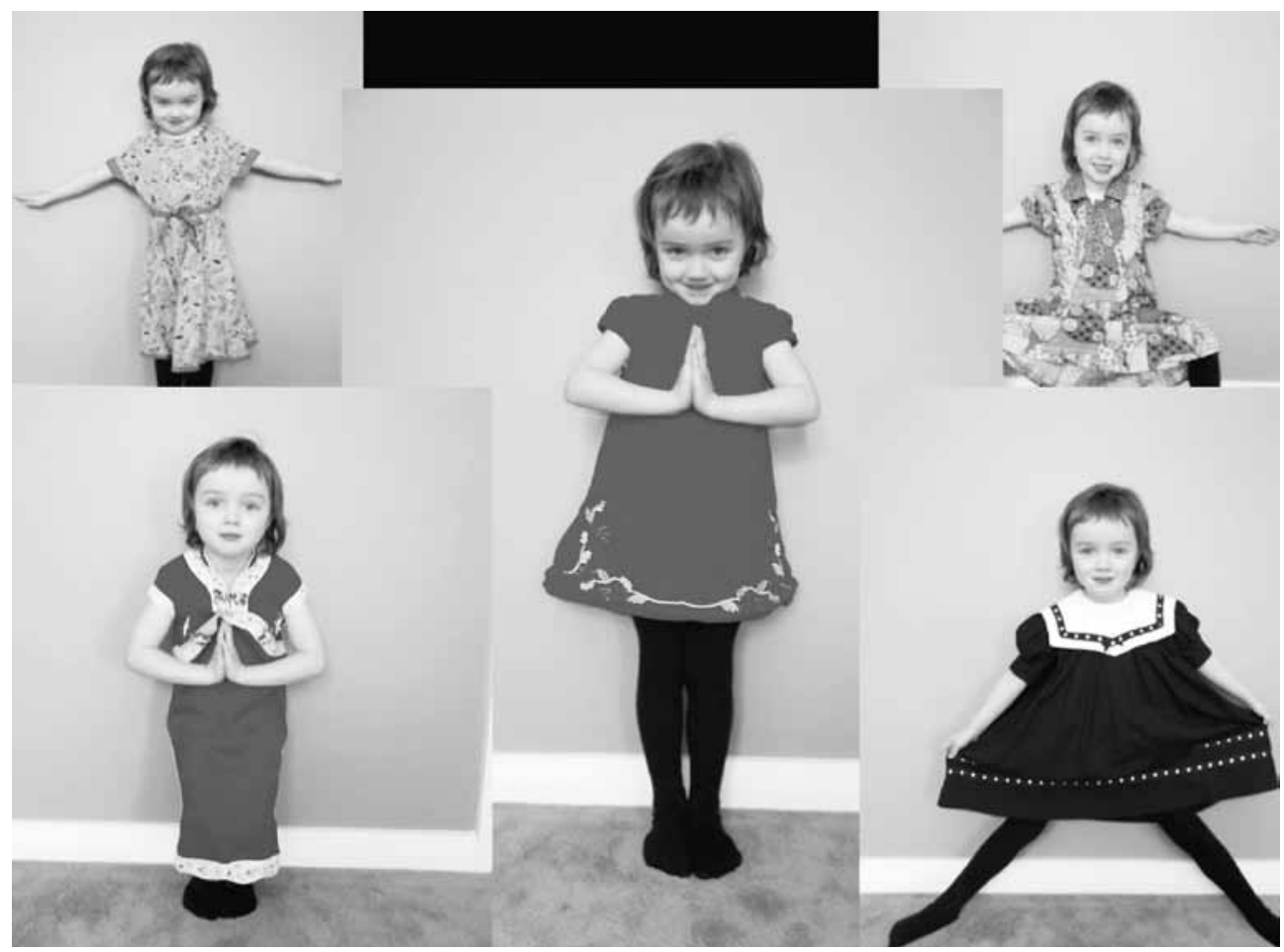

Figure 1: Kylie's dresses

Travel objects, such as souvenirs, may be assigned a superior value on account of their coming from elsewhere (Haldrup, 2015). Here the dress is important to Kylie, and she wants to show it off in preschool. The dress may represent a strong emotional connection with her dad, also connecting her to Indonesia, while marking a distant place there. Objects have traces inscribed upon them of where they originate from. They can also represent an imagined place of origin and an actual place of usage, or can gain relevance because of their mobility (Hahn \& Weis, 2013). In response to my question, Kylie connects wearing this dress with lots of different places and children who wear it in the distant place. Kylie's dress also symbolises her emotional 
attachment to her dad. As Haldrup (2015, p. 52) explains, "the 'magical capabilities' of everyday objects ... animat[e] them with affects and emotions, feelings of remembrance, affection".

The red shiny silk, golden threads, intricate flowers and sequins continue to capture the attention of Kylie's hand and her eyes, captivating them into exploring these new sensations. Her embodied presence overshadows our conversation. It is as if, through stroking and wearing her dresses, she not only engages with the story of how she got them and the emotions she feels for her father, but experiences affect, through feeling the silk, and perhaps a distant place (see Anderson, 2006, 2009). The sensory and affective processes work on Kylie as 'magic' (Bennett, 2001). In Bennet's (2001) understanding, to be enchanted includes "a condition of exhilaration or acute sensory activity. To be struck and shaken by the extraordinary that lives amid the familiar and the everyday" (p. 4) and "to be simultaneously transfixed in wonder and transported by sense, to be both caught up and carried away." (p. 5). Enchantment, both in its pleasurable and mysterious form, is more of an affective and somatic event than a cognitive and symbolic one. As Kylie becomes enchanted by her dress, possible affective 'routes' emerge between her locality, the farm she lives on, the preschool where she wears the dress, the place from where her dress originates and the places where other children wear these dresses.

Kylie's dresses hold possibilities that cannot be reduced to either their material forms or their symbolic meanings. Their materiality, stories, and the emotions and affects they produce, create affective 'routes' that also help to narrate her identity. Wearing the different dresses makes Kylie anew; a different girl emerges each time she encounters their textures, colours and stories. My question makes her wonder about the children who wear these dresses in a distant place. She perhaps also wonders about the commonalities and differences between her and the children there. Her wonder and the 'magic' of wearing these dresses connect the distant place and everyday life there.

Kylie's imagination of a distant place and her sense that her dress is something exotic but definitely new and different can also be understood as an imagination fuelled by Orientalism, in which the Occident imagines the Orient (Said, 1978). Terming these 'imaginative geographies', Said emphasised the spatial nature of these imaginations. The interactions between imagination and subjects are wrought with power. Encompassing 'home' and the 'abroad' that is far away they emphasise the difference and create 
a power relation between those at home and those whose lives have been colonialised by Oriental imaginations. This positioning is further amplified, as Kylie, a white girl, places her hands in a stereotypical representation of a subservient gesture associated with a sense of 'Chineseness' and femininity in countless Western films (See photo in Figure 1). This gesture represents a very stereotypical image of the women and girls who wear these dresses, which could reflect how Kylie imagines them and could provide her with a means to help construct her self in juxtaposition to these subservient others. In the above situation, however, Kylie brings out the sameness. Children in lots of places, including Indonesia, are just like her, and go to school in these dresses and perhaps wear them on a farm like she does. Nonetheless, in itself the traditional dress carries old-fashioned images that are fixed in time and do not characterise how children live their everyday lives in those places today.

The dress is a sensual form of emplacement that could create power hierarchies between the home and self, and a distant place and others through an Oriental imagination. Here, however I would suspend this interpretation since Kylie assigned value to this dress through her emotions towards her father and created a connection between her places and this distant place and to children just like her who wear these dresses in different places in a way that draws on similarities and continuities with other places. The dress created a 'route', drawing on an old-fashioned image, between the preschool and a distant place, as the children in the preschool marvelled at her dress and learned about her father's travels. In the next situation, another souvenir, a girl's braid, creates a 'route' to Fiji as children mimic this type of hairstyling in their activities.

\section{Hairstyle from Fiji}

Colourful plastic beads that can be plaited into children's hair appear at the preschool after some of the families visit Fiji, a popular holiday destination. The beads appeal to the children, who touch and explore them, turning them over, and investigating how they surround the many plaits. The dress-up area turns into a hairdresser's salon where the plaited hair with beads becomes an instant activity and fashion, and the children and dolls are paraded around the room with their new aesthetic.

The hair plaits and beads articulate the 'route' that connects the preschool's home area with the beaches of Fiji, where skilled woman bead hair as a tourist attraction. The new hairstyle becomes an instant fashion as the 
children appropriate it. The hair braid souvenir appears in the preschool as a stereotypical representation of a distant place and culture and sheds light on Fiji's colonial history. In the children's hair salon, the objects acquire a new identity through their 'spatial embodiment', the craft beads become hair beads, the plaited hair becomes Fijian style. In a similar manner, the plaited hair, beads and the feel of the beaded plaits afford the children new identities.

The consumption of the material objects of travel can be understood, as Franklin (2003, p. 2) contends, as a "central component of modern social identity formation and engagement" that is "infused into the everyday". Through these material objects, cultural identities are appropriated, constructed and traded as part of a touristic exchange that mediates a sense and the memory of a place (Morgan \& Pritchard, 2005). Tourists, such as these children, can gain prestige within their group through the purchase of 'ethnic' artefacts, such as the hair braid, because of the value of the international travel and multiculturalism symbolised in these arts. The hair braid becomes woven into an everyday activity in the preschool, evoking associations of 'exotic frontiers' and geopolitical power relations. A local black woman braids the hair of a white tourist child. The hair braid transcends the tourist encounter on the beach, which framed its purchase, and the preschool. This in between-ness connects the distant place to the preschool, just as the souvenir "contracts the world in order to expand the personal" (Stewart, 1993, p. xii, in Morgan \& Pritchard, 2005) and the children's activity in the preschool conjures a part of the world.

In this situation, when considering the meaning of the hair braid and related children's activity, the stereotypical image with its colonial charge and the orientalism embedded in its symbolism and production cannot be sidelined as in the previous situation with the dress. The hair braids, with their sensual capacities, bring particular imaginations of this part of the world into the children's play that reproduce geopolitical power relations related to colonial histories and imperialism, and exoticise the other in the distant place.

A number of research studies have examined children's imaginative geographies of distant places, many focusing on 'Third World' countries, such as Africa (Harrington, 1998) or Brazil (Picton, 2008) or on more affluent countries such as Japan (Taylor, 2009) or New Zealand and Britain (Holloway $\&$ Valentine, 2000b). This body of research not only illustrates how constructions of others help to create children's identities, but also explores the 
sources and importance of stereotypical understandings of distant places in creating difference along geopolitical power lines. They also draw attention to how children emphasise the sameness of their home and the distant places and how these imaginations can be and should be contested through curricula and pedagogies that encourage children to view places in their diversity, and along a continuum and in continuity, rather than in terms of difference and contrast (Picton, 2008). Most importantly, together these studies demonstrate the ways in which these images, imaginations and ideas contribute to children's knowledge about the world, their positionings towards distant others and their identity formation.

As illustrated in the symbolic play performed in the tent, the sensation of wearing a dress from a faraway place, and the colonial world invoked in the hairdresser's salon, children produce multiple worlds and re-iterate identities where the discursive reference points of their performance originate in distant places and create connections or 'routes'. Images, imaginations and ideas of distant places move children and are actively present in and shape children's activities in the preschool and their identities. They also create visible directions of cultural and economic flows, in the privilege of the global travelling business elite, such as Kylie's father or the relatively wealthy white tourist who travels to Fiji from Australia for a cheap holiday, and reiterate the power structures of colonialism, imperialism and global capitalism through their uncritical consumption of souvenirs. While in the tent and through the dresses, the children drew out similarities between their lives and the lives of the children in distant places, creating perhaps sources for a range of cosmopolitan sensibilities, stereotypical images and imaginations, such as the hair braid from Fiji for instance could reproduce a colonial engagement with difference that makes the preschool children different and superior to distant others. Through this latter kind of experience of distant places and others, it can also be argued, that they acquire a desire for an advantageous strategic positioning within current flows of mobility, the global labour market, and tourism, such as that of Kylie's dad or the families who travelled to Fiji, instead of building a moral sense of solidarity or openness to the 'Other' with their engagements (Rizvi, 2009).

\section{Multiple Worlds in the Preschool: Some Non-Conclusive Thoughts}

The global is present in children's everyday preschool lives in at least two ways. First, there is the way in which the global economy, ECEC policies 
and international frames indirectly shape children's environments through the regulations, cultures, norms and rules they institute (see Millei \& Jones, 2014). Second, distant places contribute to children's production of multiple worlds through the many 'routes' they bring to place - with the images, ideas and imaginations relating to those places as well as objects from those places -, and through which children construct a 'global sense of place' (Massey, 2005). The elements of the distant places brought via these 'routes' inform the quality of the preschool place in which the preschool children are emplaced. They offer children particular kinds of spatial embodiments, new or different 'lives' and associated identities as they relate to distant spatialities. As the children 'live' in their preschool tent in Buenos Aires, fashion themselves with dresses and hair braids brought from elsewhere, they experience these connected spatialities in embodied ways and through sensory experiences. While children create and imagine these distant places and perform associated identities, multiple worlds are being produced in the preschool. In this way, the world becomes routinely incorporated into everyday life as it is being spatially negotiated and through the spatial performances of identities. Viewing the place of the preschool as 'rooted' (as is prevalent in ECEC research) while also emphasising its 'routedness' using Massey's theory not only helps us explore the wider processes that shape children's everyday lives within that place, but also points to the global power hierarchies in which children's lives are embedded and that shape children's views and identities in concrete ways.

In the current context of the global knowledge economy, previously unseen levels of interconnectedness are now visible through the new media and mobility, and education policies and heightened scholarly interest focus on how experiences derived from this context can be shaped by curricula and pedagogy that can create a new type of sociability. Studies exploring cosmopolitanism refer to an abstract notion of openness and awareness and new types of engagement with the world and others (Duhn, 2006; 2014). However, many of these studies, as Skey (2012) argues, remain quite vague in their efforts to capture or define what they term as openness and how it emerges in people. Skey (2012, p. 473) proposes that cosmopolitanism should be understood as "periodically articulated, embodied and materialized, rather than [as] being an inherent property of particular individuals, groups or situations". This view re-orients explorations to focus on the everyday activities through which cosmopolitanism emerges. Existing research on children's engagement with distant places generally considers their ideational forms and therefore only marginally addresses how these are incorporated into children's everyday activities. In my analysis, there- 
fore, I have paid special attention to how images, ideas and imaginations of distant places participate in the everyday activities as place, children's bodies and objects entangle and create sensory experiences in which the worlds are created and experienced. Through the performative, spatial, embodied and sensory processes described above, researchers can empirically explore the potentiality to experience and enact forms of openness and awareness, investigate ways of engaging in a more responsible and just manner with the world, and develop ways of seeing and acting upon the world in the 'doings' of everyday life.

For this to happen, researchers and educators need to pay more attention to and critically engage with children's expressions and performances of social knowledge about distant spatialities in everyday preschool activities. Focusing on objects, feelings, sensations and modes of experiencing helps us approximate this knowledge and indicates the power relations children associate with them. As I have illustrated, children can draw similarities between distant places and their own place, and create continuities between them in their 'doings'. Even in these situations it is important to keep sight of the fact that places change continuously, and images and ideas can easily become old-fashioned. Therefore, it is important to acknowledge that even if these are less harmful ways of imagining and connecting to different places, there is no authentic representation of that place. In the above situation, the children also drew on stereotypes that hinge upon harmful and oppositional binaries that associate superiority with the child's place and identity. Picton (2008, p. 246) therefore suggests "that pupils need to be taught about diversity and continuum as a way of thinking/ a way of seeing the world", and I would also add 'doing' the world, where no authentic representation or enactment of place exists. He argues for a focus on and a more nuanced understanding of the similarities, "and a positive perspective on difference (as opposed to difference defined by lacking/absence/negativities) and diversity [a]s desirable" (Picton, 2008, p. 246).

Critical engagement with one's own ideas, sensory experiences and 'doings' of distant places and others could become the seed of ethical, cultural and political engagements with others and with difference, and offer starting points for cosmopolitan conversations (Rizvi \& Beech, 2017). Children's engagement with distant spatialities as part of everyday activities can thus create the necessary conditions for 'doing' and learning solidarity, democracy and rights (besides their sensemaking) that is perhaps more attuned to the ways in which children experience and enact their world. As part of activities and notions of a more just world, openness to difference and eth- 
ics can be enacted with children in embodied and sensorial ways. This can also create dimensions in ECEC through which contributions to a more just world can be made (Hägglund \& Pramling Samuelsson, 2009), and on which global and cosmopolitan citizenships can be formed.

\section{Acknowledgement}

I thank the director and educators of the preschool and the children for their contributions to this research and the Jean Denton Memorial Scholarship that funded this project. I am also grateful for Sabine Bollig and the anonymous reviewers' critical and constructive comments that helped me think through this article.

\section{References}

Anderson, B. (2006). Becoming and being hopeful: Towards a theory of affect. Environment and Planning D, Society \& Space, 24, 733-752.

Ansell, N. (2009). Childhood and the politics of scale: Descaling children's geographies? Progress in Human Geography, 33, 190-209.

Australian Government Department of Education, Employment and Workplace Relations (AGDEEWR) (2009). Belonging, Being and Becoming: The early years learning framework for Australia. https://www.education.gov.au/early-years-learning-framework-0 Accessed 18 March 2016.

Bennet, J. (2001). The enchantment of modern life. Princeton: Princeton University Press.

Bollig, S. (2015). The multiple geographies of early childhood education and care: An ethnographic approach to the places and spaces of young children's care arrangements. In S. Bollig, M. S. Honig, S. Neumann, \& C. Seele (Eds.), MultiPluriTrans in educational ethnography (pp. 99-118). Bielefeld und Columbia.

Bretherton, I. (1984). Representing the social world in symbolic play: Reality and fantasy. In I. Bretherton (Ed.), Symbolic play: The development of social understanding. (pp. 1-40) Orlando, Florida: Academic Press.

Butler, J. (1990). Gender trouble. London: Routledge.

Christensen, P. (2003). Place, space and knowledge: Children in the village and the city. In P. Christensen, \& M. O'Brien (Eds.), Children in the city. Home, neighborhood and community (pp. 13-28.) London: Routledge.

Crang, M., \& Thrift, N. (2000). Thinking space. London: Routledge.

Disney, A. (2005). Children's images of a distant locality. International Research in Geographical \& Environmental Education, 14(4) 330-335.

Duhn, I. (2006). The Making of global citizens: Traces of cosmopolitanism in the New Zealand early childhood curriculum, Te Whāriki. Contemporary Issues in Early Childhood, 7( 3) 191-202.

Duhn, I. (2014). Being and becoming cosmopolitan in early childhood curriculum: 'Roots', 'wings' and cosmopolitan citizenship. Global Studies of Childhood, 4(3) 224-234. 
Franklin, A. (2003). Tourism: An introduction. London: SAGE Publications.

Gregson, N., \&Rose, G. (2000). Taking butler elsewhere: Performativities, spatialities and subjectivities. Environment and Planning D: Society and Space, 18(4) 433-452. Hackett, A., Procter, L., \& Kummerfeld, R. (2018). Exploring abstract, physical, social and embodied space: Developing an approach for analysing museum spaces for young children. Children's Geographies, 16.

Hackett, A., Procter, L., \& Seymour, J. (2015). Children's spatialities. Embodiment, emotion and agency. London: Palgrave Macmillan.

Hägglund, S., \& Pramling Samuelsson, I. (2009). Early childhood education and learning for sustainable development and citizenship. International Journal of Early Childhood, 41(2) 49-63.

Hahn, H. P., \& Weis, H. (2013). Mobility, meaning and transformations of things: Shifting contexts of material culture through time and space. Oxford: Oxbow Books.

Haldrup, M. (2017). Souvenirs: Magical objects in everyday life. Emotion, Space and Society, 22, 52-60.

Holloway, S., \& Valentine, G. (2000a). Children's geographies and the new social studies of childhood In S. Holloway, \& G. Valentine (Eds.), Children's geographies: Playing, living, learning. (pp. 1-28) London: Routledge.

Holloway, S.L., \& Valentine, G. (2000b). Corked hats and Coronation Street: British and New Zealand children's imaginative geographies of the other. Childhood, $7(3)$ 335-357.

James, A., \& Prout, A. (1997). Constructing and reconstructing childhood: Contemporary issues in the sociological study of childhood. 2nd ed. London: Routledge Falmer.

Katz, C. (2004). Growing up global: economic restructuring and children's everyday lives. Minnesota: University of Minnesota Press.

Massey, D. (1991). A global sense of place. Marxism Today, (38), 24-29.

Massey, D. (1994). Space, place and gender. Minneapolis: University of Minnesota Press.

Massey, D. (1998). The spatial construction of youth cultures. In T. Skelton, \& G. Valentine (Eds.), Cool places: Geographies of youth cultures (pp. 121-129). London and New York: Routledge.

Massey, D. (2005). For Space. London: SAGE.

McKendrick, J. (2000). The geography of children: An annotated bibliography. Childhood, 7 (3) 359-387.

Millei Z., \& Jones, A. (2014). Australian early childhood education and care policy and the (re)production of global imaginary. International Journal of Early Childhood, 46(1), 63-79.

Millei, Z., \& Rautio, P. (2017). 'Overspills' of research with children: an Argument for slow research. Children's Geographies, 15(4), 466-477.

Mitchell, C., \& Reid-Walsh, J. (2002). Researching children's popular culture: The cultural spaces of childhood. London: Routledge.

Morgan, A., \& Pritchard, A. (2005). On souvenirs and metonymy: Narratives of memory, metaphor and materiality. Tourist Studies, 5, 29-53.

Penn, H. (2002). The World Bank's view of childhood. Childhood, 9(1), 118-132.

Penn, H. (2011). Travelling policies and global buzzwords: How international non- 
-governmental organizations and charities spread the word about early childhood in the global South. Childhood, 18(1), 94-113.

Picton, J. O. (2008). Teaching and learning about distant places: Conceptualising diversity. International Research in Geographical and Environmental Education, 17(3), 227-249.

Pink, S. (2009). Doing sensory ethnography. London: Sage.

Procter, L. (2013). Exploring the role of emotional reflexivity in research with children. Emotion, Space and Society, 9, 80-88.

Prout, A. (2005). The future of childhood. London: Routledge Falmer.

Rizvi, F. (2009). Towards cosmopolitan learning. Discourse: Studies in the Cultural Politics of Education, 30(3), 253-268.

Rizvi, F., \& Beech, J. (2017). Everyday cosmopolitanism: The challenges of academic leadership. In S. Feng, \& M. Wood (Eds.), Cosmopolitan perspectives on academic leadership in higher education. London and New York: Bloomsbury.

Said, E. (1978). Orientalism. London: Penguin.

Secor, A. (2004). There is an Istanbul that belongs to me: Citizenship, space and identity in the city. Annals of the Association of American Geographers, 94(2), 352368.

Skey, M. (2012). We need to talk about cosmopolitanism: The challenge of studying openness towards other people. Cultural Sociology, 6(4), 471- 487.

Thrift, N., \& Dewsbury, J.-D. (2000). Performativity and the event: Enacting a philosophy of difference. Environment and Planning D: Society and Space, 18(4), 473-496. United Nations High Commissioner for Human Rights. (1989). Convention on the Rights of the Child [Electronic Version]. Retrieved August 24, 2012, from http:/ /www. ohchr.org/EN/ProfessionalInterest/Pages/CRC.aspx

\section{Author:}

Zsuzsa Millei, Assoc. Professor

University of Tampere

Faculty of Education

Institute for Advanced Social Research

Kanslerinrinne 1

Tampere

$\mathrm{FI}-33014$

Finland

E-mail: Zsuzsa.Millei@uta.fi 